\title{
Amor ou risco? Refletindo sobre sentidos, regulações e orientações a respeito do leite materno a partir de casos de "amamentação cruzada"
}

Love or risk? Reflecting on meanings, regulations and prescriptions around breast milk, through "crossnursing" episodes

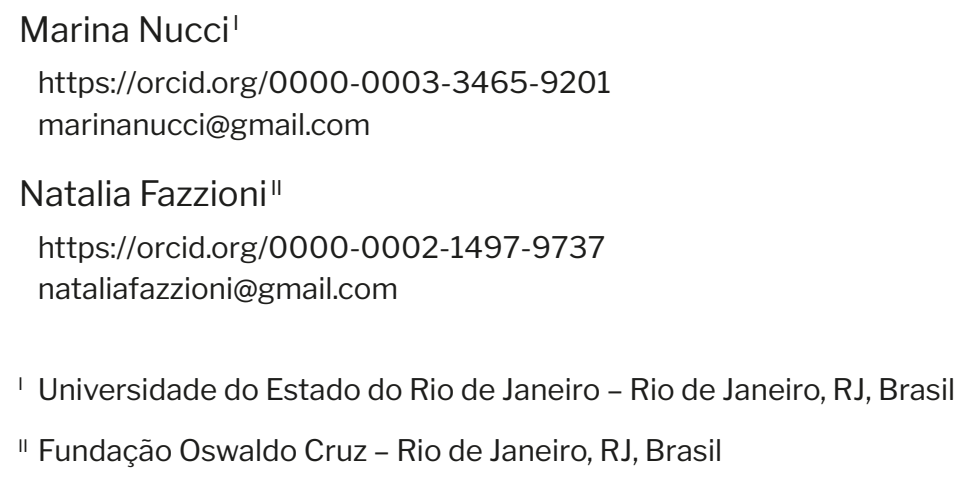




\title{
Resumo
}

Neste artigo refletimos sobre os sentidos atribuídos ao leite materno, e os diferentes atores e mecanismos morais que orientam e regulam a prática da amamentação. Nosso foco é a "amamentação cruzada", ato em que um bebê é amamentado por alguém que não sua própria mãe - contraindicado pelo Ministério da Saúde pelo risco de transmissão de doenças. A partir da análise de materiais diversos, como reportagens e postagens em redes sociais, observamos como casos de amamentação cruzada repercutem a partir de um "script", em que profissionais de saúde alertam para tais riscos, ao mesmo tempo que atestam a segurança dos bancos de leite, onde o leite doado é pasteurizado. Assim, analisamos ambiguidades em torno do leite e da amamentação, chamando atenção para os processos históricos de estabelecimento dos bancos de leite no Brasil. Por fim, à luz das discussões sobre cuidado, debatemos diferentes modos de vivenciar família, maternidade e amamentação.

Palavras-chave: amamentação; maternidade; saúde; risco.

\begin{abstract}
In this article we explore the meanings attributed to breastmilk, and the different actors and moral mechanisms that guide and regulate the practice of breastfeeding in Brazil. Our focus is "cross-nursing", an act in which a baby is breastfed by someone other than his own mother - contraindicated by the Ministry of Health, due to the risk of disease transmission. From the analysis of various materials, such as reports and posts on social networks, we observe how cases of cross-nursing resonate from a "script", in which healthcare professionals warn of such risks, while attesting to the safety of human milk banks, where donated milk is pasteurized. Thus, we analyzed ambiguities around breast milk and breastfeeding, drawing attention to the historical processes of establishing human milk banks in Brazil. Finally, in the light of discussions about care, we discussed different ways of experiencing family, motherhood and breastfeeding.
\end{abstract}

Keywords: breastfeeding; motherhood; healthcare; risk. 


\section{Introdução}

Este artigo é fruto da interlocução entre duas pesquisadoras, a partir de seus respectivos interesses de pesquisa de pós-doutorado e do cruzamento entre materiais que foram sendo mapeados e coletados durante o processo de reflexão sobre o tema que será discutido nas páginas seguintes: a amamentação cruzada. ${ }^{1}$ A origem dos materiais é diversa, com enfoque em casos publicizados na mídia impressa, redes sociais e programas de televisão, além de um documentário sobre o tema.

Não é irrelevante dizer ainda que se trata de duas pesquisadoras e mães que viveram a experiência da amamentação em meio a uma das mais desafiadoras tarefas em suas trajetórias acadêmicas: a escrita de uma tese de doutorado. Atravessadas pela experiência da maternidade e da amamentação, por caminhos distintos, chegamos às mesmas inquietações marcadas, por um lado, pelas políticas que orientam os protocolos de amamentação hoje no Brasil, e, por outro, pelo amplo leque de experiências em torno dessa prática que pudemos observar e conhecer a partir da proximidade com o assunto em nossas vidas pessoais, inicialmente, e como tema de pesquisa hoje.

Assim, não foi possível viver tal processo sem indagar sobre as concepções presentes entre os diferentes atores sociais e mecanismos que orientam e regulam a prática da amamentação em seus aspectos morais, legislativos, econômicos, políticos e sociais no país, o que se somou a um esforço de compreensão de uma literatura internacional a respeito desse mesmo processo em outras realidades, resultando em algumas das reflexões apresentadas a seguir.

\section{Ato de amor ou prática de risco? Um caso introdutório}

Em fevereiro de 2020, uma foto veiculada nas redes sociais e na mídia local de Belo Horizonte, Minas Gerais, causou forte repercussão. Nela, uma policial militar fardada aparece amamentando o bebê de uma mulher que era atendida

1 Marina Nucci investiga a atuação de "consultoras em amamentação" - profissionais que auxiliam mulheres a amamentar -, procurando refletir sobre suas trajetórias, e a articulação entre ciência, natureza e moral nos discursos sobre aleitamento. Natalia Fazzioni pesquisa a relação entre amamentação, comunicação e políticas públicas de saúde a partir de uma etnografia com usuárias de uma plataforma virtual sobre bebês e maternidade. 
naquele mesmo momento na delegacia, por um caso de violência doméstica. Segundo a policial, o bebê de três meses chorava de fome enquanto a mãe prestava queixa. Como o bebê costumava ser alimentado apenas através da mamadeira, que havia sido deixada em casa, a solução acabou sendo apresentada pela policial e consentida pela mãe. A prática caracteriza aquilo que é chamado hoje tecnicamente de amamentação cruzada, objeto de análise deste artigo, a partir da qual pretendemos refletir conjuntamente sobre o processo de construção de um saber científico sobre o tema - pensando, sobretudo, no caso do Brasil - e as diferentes relações e sentidos atribuídos à amamentação e ao leite materno na sociedade brasileira.

Apesar de o leite materno ser considerado "o melhor alimento para bebês" (Brasil, 2015), há muitos conflitos associados à amamentação, prática cercada de vigilância e escrutínio moral, e que carrega complexa bagagem simbólica e ideais de maternidade e feminilidade (Badinter, 1985; Blum, 1993). Assim, ao mesmo tempo que a amamentação é vista como um "nobre ato", e o é leite percebido como uma substância "preciosa", impregnada de qualidades medicinais e terapêuticas - marcado em expressões como "ouro líquido", "amor em gotinhas" ou "cada mamada é uma vacina" -, com frequência associa-se também o leite materno a uma excreção corporal suja, possível contaminante, e a amamentação a um ato obsceno que deve ser ocultado (Badinter, 1985; Cassidy; El-Tom, 2015; Shaw, 2004, 2007; Wilson, 2018). Essa ambiguidade revela também uma ambivalência em relação à capacidade de mulheres criarem seus filhos fora do escrutínio e da autoridade médica (Hausman, 2010).

Nas políticas contemporâneas que envolvem o aleitamento, a prática da amamentação cruzada é vista como uma atividade desviante e arriscada (Shaw, 2007). No caso específico do Brasil, como discutiremos neste artigo, ela é também considerada uma prática "antiga" e "ultrapassada", que foi revista à luz do conhecimento científico, e que atualmente seria realizada apenas por mulheres que "ignorariam" os riscos e as recomendações sanitárias, necessitando, portanto, serem informadas e educadas.

Exibida no programa de televisão Balanço Geral MG da TV Record (Conheça..., 2020), a notícia sobre o caso da policial militar foi acompanhada de uma entrevista com uma pediatra, que alertava sobre "os riscos da amamentação cruzada". A pediatra entrevistada lembrava que, devido aos "riscos de transmissão de doenças infectocontagiosas às crianças, sobretudo o HIV e o HTLV, a prática 
não é recomendada". Atentando ainda que para aquelas que desejassem doar leite materno, o procedimento mais adequado seria a procura por um banco de leite humano, onde ele seria examinado e pasteurizado. Como veremos, a reportagem segue uma espécie de "script" constante na visibilização na mídia de casos como este: há a presença de um profissional de saúde que alerta para os riscos da prática, desaconselhando-a, ao mesmo tempo que atesta, em oposição, a segurança dos bancos de leite.

Já nas redes sociais, em uma postagem no perfil oficial da própria Polícia Militar de Minas Gerais (2020), a foto da sargento amamentando a criança trazia a seguinte descrição: "Ato de amor: A Sargento Marcilaine estava na delegacia de mulheres e uma criança, filha de uma vítima de Maria da Penha, estava com fome. A Sargento não hesitou e alimentou, com muito amor, a criança. Servir e proteger sempre." Os quase 500 comentários seguidos abaixo da postagem revelam os muitos sentidos atribuídos e despertados pela amamentação cruzada, entre os quais se destacam: elogios à atitude da policial, proveniente de um "instinto materno"; ${ }^{2}$ referência às "amas de leite" na história do país e prevalência da prática entre mulheres da mesma família ou com relação de intimidade até os dias de hoje, ${ }^{3}$ riscos para a saúde e riscos morais contidos no ato de amamentar uma criança que não seja seu próprio filho; ${ }^{4}$ entre outros.

O compartilhamento do leite humano com bebês que não sejam filhos daquela mulher que o produziu pode se dar de diferentes modos, e cada uma dessas práticas possui especificidades históricas e culturais, e carregam sentidos distintos (Shaw, 2007). De modo esquemático, podemos dividi-lo

2 Um comentário diz, por exemplo: “[...] nos dias de hoje, onde as pessoas se preocupam mais com detalhes do que com o amor, o gesto dessa policial é indescritível, é de amor de mãe, amor puro, mesmo pq o amor de mãe é o que mais se aproxima do amor de Deus."

3 Um exemplo é: "Minha mãe amamentou meu primo, filho da minha tia, irmã dela. E essa minha tia amamentou minha irmã algumas vezes também. Nenhum dos dois teve problema algum, até onde eu sei. E as amas de leite amamentavam os filhos das 'sinhás'. Não sei se há alguma comprovação científica de que há problema na chamada 'amamentação cruzada'."

4 “Não existe mais 'ama de leite'. O que existe são doadoras de leite materno para hospitais maternidade, onde o leite doado é processado para esterilização do leite, eliminando qualquer tipo de antígeno e qualificando esse leite para ser doado. Amamentar diretamente no peito deve ser feito somente pela própria mãe." 
em duas formas principais: tendo sido ordenhado e oferecido através de algum recipiente (mais comumente uma mamadeira) ou compartilhado diretamente na mama, através do ato de se amamentar em si.

No primeiro caso, o leite pode ser compartilhado através de bancos de leite, ou em redes informais de trocas (ou mesmo de vendas, em países em que, diferentemente do Brasil, vender substâncias corporais não é proibido). Já a segunda situação, em que um bebê mama diretamente em uma mulher que não é sua mãe, pode ser dividida entre amamentação com amas de leite ou amamentação cruzada. De modo geral, o caso das amas de leite demanda uma situação contratual, na qual há alguma forma de remuneração, e, historicamente, se dá a partir de uma relação assimétrica, envolvendo relações de exploração (Shaw, 2007). No Brasil, como veremos, essa é uma prática com forte ligação com a escravidão.

Já no caso da amamentação cruzada, trata-se de arranjos informais, que não envolvem pagamento, e que são estabelecidos a partir de relações simétricas e de reciprocidade. Na amamentação cruzada, portanto, mulheres amamentam bebês umas das outras, quando há desejo e/ou necessidade, pressupondo uma troca ou compartilhamento de tarefas (Shaw, 2007).

Por fim, deve-se sinalizar mais recentemente a existência de dois outros tipos de situação de compartilhamento de leite sem a existência de um vínculo biológico, que não se enquadram em nenhuma dessas citadas acimas. Trata-se do caso de mães adotivas e mães não gestantes em casais homoafetivos, que desejam amamentar e logram realizar tal aspiração a partir de um método de indução à lactação com uso de hormônios. ${ }^{5}$ Temas já clássicos para os estudos sobre família e parentesco na antropologia contemporânea, a adoção e a homoparentalidade são exemplos centrais na crítica ao dualismo social e biológico (Carsten, 2014; Strathern 1995) presentes nos "velhos modelos" de análise antropológica de parentesco criticados inicialmente por Schneider (1968). Ambas as situações apontam para a complexidade do tema, levando-se em conta a existência do vínculo considerado imprescindível para o ato de amamentar, o da maternidade, entretanto, sem uma relação de consanguinidade.

5 Para um relato autobiográfico desse processo, ver Tiboni (2019). 
Assim, as diversas formas de compartilhamento, e a que nos interessa em especial neste artigo, a chamada amamentação cruzada, evidenciam a característica intercorporal do leite - já que envolve trocas de fluidos corporais e empréstimos de partes do corpo, como o mamilo e a mama -, tensionando construções individualistas da identidade materna. Por isso mesmo, a prática acaba por colocar em questão a coerência com a qual a maternidade é construída pelo individualismo ocidental, ameaçando dissolver fronteiras e perturbar o "vínculo sagrado" mãe-filho (Shaw, 2004).

\section{Naturalização, contraindicação e invisibilidade científica: construção de um problema}

Em uma exploração inicial sobre o tema, em conversas com familiares e amigas, observamos uma forte presença, entre mulheres de diferentes gerações e origens sociais, de narrativas sobre amamentação cruzada. Tias, irmãs, vizinhas, "mães de leite", babás e empregadas domésticas são algumas das personagens envolvidas nessas experiências de amamentar ou ter sido amamentada por outras mulheres, revelando ser esta uma situação comum e naturalizada entre a população brasileira, mesmo considerando sua contraindicação pelos órgãos de saúde.

Desde 1995, o Ministério da Saúde regulamenta questões relativas ao aleitamento materno, sobretudo no que tange aos riscos relacionados ao HIV/AIDS, contraindicando a amamentação de mães HIV positivas, e contraindicando o aleitamento cruzado, pelos riscos de transmissão do vírus (Barbieri; Couto, 2012). A Portaria n 2.415 (Brasil, 1996), de dezembro de 1996, determina que:

I - o aleitamento materno cruzado não deve ser realizado, incluindo aquele às vezes praticado nos sistemas de alojamento conjunto pelas tradicionais amas-de-leite;

II - as mulheres infectadas pelo HIV não devem amamentar seus próprios filhos, nem doar leite;

III - os filhos de mães infectadas pelo HIV que necessitam do leite materno como fator de sobrevivência, poderão receber leite de suas próprias mães, desde que adequadamente pasteurizado. 
Embora exista essa proscrição do Ministério da Saúde, este não é o mesmo posicionamento de outros países, ou mesmo da Organização Mundial da Saúde (OMS). Como apontam Von Seehausen, Oliveira e Boccolini (2017, p. 1674):

Segundo a Organização Mundial da Saúde (OMS), nas excepcionais condições em que o leite de uma mulher não é adequado ou não está disponível para a alimentação de seu filho, a escolha da melhor alternativa depende de circunstâncias individuais ou coletivas, como catástrofes. Tais alternativas são: amamentação realizada por uma lactante saudável, leite ordenhado de outra lactante, leite obtido em bancos de leite humano ou substituto ao leite humano.

É necessário salientar que a maioria dos estudos sobre amamentação costuma partir de uma perspectiva médica e de saúde pública, havendo poucas análises sobre experiências que vão além do que seriam consideradas as "boas práticas" incorporadas nesses discursos (Shaw, 2007). Isso pode ser especialmente observado no caso da amamentação cruzada. Apesar de, anedoticamente, a prática parecer continuar bastante presente na sociedade brasileira, poucos são os estudos a respeito.

Entre os estudos disponíveis, destacamos dois. O primeiro, realizado por Pereira (2014), investigou a prevalência do aleitamento cruzado entre mulheres atendidas na Estratégia da Saúde da Família em Belém, no Pará. Nessa pesquisa, metade das entrevistadas já havia amamentado crianças que não eram seus próprios filhos - em geral filho de alguma vizinha ou parente. As principais razões apontadas eram a dificuldade em conseguir amamentar e a ausência (temporária ou definitiva) da mãe. A superioridade do leite materno em relação a outros alimentos era citada como um motivo que legitimava $o$ ato, assim como a ideia de solidariedade. A preocupação com possíveis riscos não estava ausente, e em geral se dava em relação a alimentos potencialmente prejudiciais ingeridos pela lactante e que poderiam passar para o bebê, mas todos os riscos seriam minimizados pelas relações de intimidade e confiança entre as mulheres.

Já em uma pesquisa com gestantes que realizaram pré-natal na rede pública em duas cidades do estado do Rio de Janeiro, Von Seehausen et al. (2017) verificaram que $43,3 \%$ das entrevistadas da cidade $1(n=250)$ e $34,5 \%$ da cidade 2 ( $n=252$ ) haviam ou amamentado outra criança que não seus próprios filhos, 
e/ou tido seus filhos amamentados por outra pessoa, na maioria das vezes alguma parente. As entrevistadas indicavam que o aleitamento cruzado, embora também pudesse ocorrer por dificuldades com a amamentação, em geral refletia um comportamento de ajuda mútua, pela necessidade de se deixar a criança sob cuidados de outra pessoa. Assim, embora desaconselhado no Brasil pelo Ministério da Saúde desde a década de 1990, a prática mostrou-se bastante prevalente, de modo que os autores concluem que:

O aleitamento cruzado deve receber mais atenção dos profissionais e instituições de saúde, pois está evidente que o posicionamento atual frente ao tema não está refletindo nas escolhas de parte significativa das mães, e é questionável. Essa prática cultural pode estar beneficiando mães que se apoiam mutuamente e bebês que recebem leite humano. Além disso, a prevalência de HIV em gestantes no contexto brasileiro é baixa $(0,4 \%)$, e a proporção de mães não testadas para o HIV na gestação e no momento do parto foi inferior a $1 \%$ em estudo recente. Portanto, amplo debate sobre o aleitamento cruzado deve ser promovido envolvendo o meio acadêmico, o setor saúde e a sociedade em geral, e investigações devem avaliar a relação entre os benefícios e os riscos inerentes ao aleitamento cruzado. (Von Seehausen et al., 2017, p. 8).

Como apontam as pesquisas acima, parece haver um hiato entre as políticas públicas e conduta profissional sobre o tema, e a percepção da própria população a respeito dela. Um exemplo bastante significativo dessa distância foi quando, em um episódio da novela O outro lado do paraíso, exibida pela Rede Globo em 2018, um personagem médico aparece em uma cena oferecendo o leite de sua esposa para uma paciente que havia acabado de dar à luz e supostamente teria "pouco leite" e não poderia amamentar seu filho. A cena gerou indignação e inúmeras respostas de órgãos oficiais, instituições e grupos de promoção à amamentação, ${ }^{6}$ atentando não só para os riscos da prática, como também criticando a ideia de que uma mulher recém-parida, ainda hospitalizada, teria pouco

6 Exemplos de instituições e grupos que se manifestaram: Sociedade Brasileira de Pediatria, Conselho Federal de Enfermagem, Fiocruz e IBFAN (Rede Internacional em Defesa do Direito de Amamentar). 
leite e seria incapaz de amamentar. ${ }^{7}$ Causou também indignação a proposta do compartilhamento do leite ter partido de um personagem que representava um profissional de saúde - médico, diretor do hospital -, que deveria conhecer seus riscos e contraindicações, e a quem caberia o papel de informar corretamente. A nota da Sociedade Brasileira de Pediatria ressalta esse ponto:

Essa atitude, tão comum no Brasil antigo, na época das amas de leite, hoje conhecida como "amamentação cruzada", é uma prática que tem contraindicação absoluta pelos órgãos oficiais de saúde. E quando um "diretor de hospital" passa essa orientação, ele está incorrendo em um erro básico e passível de punição, em caso de dano à saúde do bebê. [...]

Esse tipo de informação equivocada (amamentação cruzada), transmitida como um "ato de amor", coloca em risco a vida de milhares de crianças que poderiam ser beneficiadas pela doação de leite materno aos Bancos de Leite Humano, onde esse seria devidamente analisado e oferecido de forma segura, sem riscos, a lactentes que necessitam desse apoio para sua sobrevivência. (Barsanti; Chencinski, 2018).

Em carta aberta, João Aprígio Guerra de Almeida (2018), da Fiocruz, coordenador da Rede Global de Bancos de Leite Humano, escreve dizendo que "considerando a importância da Rede Globo na formação de opinião e particularmente no tocante ao seu compromisso com a infância brasileira, solicitamos a gentileza de [que] neste mesmo veículo [...] sejam incluídas mensagens que evidenciem os riscos da prática". Do mesmo modo, a Sociedade Brasileira de Pediatria também solicitou a "todos os veículos de comunicação, em especial à emissora responsável pela novela [...], que ajudem a disseminar as vantagens do aleitamento junto aos brasileiros, ressaltando a forma correta de aderir a esse método que traz inúmeros benefícios às futuras gerações (Conselho Regional de Medicina do Estado do Rio de Janeiro, 2018, grifo nosso).

A emissora de televisão, enfim, se retratou publicamente dizendo que os roteiristas desconheciam a contraindicação e exibiu, em seguida, um episódio

7 Isso porque no período pós-parto há apenas o colostro, líquido produzido em quantidade pequena, mas compatível às necessidades do bebê. O leite "maduro" só passa a ser produzido horas ou dias depois, na "apojadura" (período conhecido popularmente como "descida do leite") (Brasil, 2015). 
onde as personagens, em um novo diálogo, reviam seu posicionamento, explicitado na seguinte fala do médico: "Pela generosidade, eu acabei me equivocando. A família da Nádia é tão próxima da nossa que eu acabei oferecendo o leite da Suzy... Só que o correto é doar para um banco de leite." A cena de retratação prossegue com a personagem da mãe do médico, que comenta: "Na minha época não tinha nada disso. Quem tinha leite em excesso dava pro bebê de quem não tinha." Ao que o médico explica: "Isso no passado era muito comum, mas não agora, mamãe, porque através do banco de leite a gente pode analisar o material doado e assim evitar doenças."

Nota-se, portanto, que quando ganham visibilidade pública no Brasil, tais situações revelam comumente um cenário bastante similar ao descrito no exemplo da policial, a saber: a ocorrência da amamentação cruzada e sua publicização inicial aponta para uma ideia de "naturalização" da prática. Logo, entretanto, instaura-se uma polêmica com reações favoráveis e desfavoráveis a ela, e, finalmente, ocorre o pronunciamento de um especialista que alerta sobre os riscos da prática e indica a existência dos bancos de leite humano como solução mais apropriada a esse tipo de situação.

Como podemos observar, o tema traz em si uma série de complexidades já brevemente ilustradas pelas situações acima, e chama atenção ainda a pouca visibilidade e presença da amamentação cruzada em pesquisas sobre o assunto, conforme já sinalizado. Nesse sentido, parece ser central olharmos para um importante ator dessas polêmicas e compreender quais sentidos ele ganha em diferentes contextos: o leite materno.

\section{UTI, bancos de leite e parentesco}

Enquanto fluido corporal, o leite materno tem a especificidade de ser uma substância produzida por um corpo para adentrar - e alimentar - outro corpo (Van Esterik, 2009), além de ser o único alimento produzido corporalmente

8 Em outro caso recente, de julho de 2019, uma "blogueira" foi criticada ao compartilhar uma fotografia em que amamentava seu sobrinho. As reportagens na mídia seguiram o mesmo "script", como é possível observar na matéria da revista Pais \& Filhos, cuja manchete dizia: "Gabi Brandt amamenta o sobrinho e nós te explicamos os perigos da amamentação cruzada” (Gimenez, 2019). 
pelo ser humano (Soler, 2017). Quando compartilhado, é um fluido capaz de gerar representações simbólicas, construir identidades e estabelecer relações entre indivíduos (Soler, 2017). Nesse processo, continua simbolicamente ligado ao corpo que o produziu, embaralhando noções sobre limites corporais, pureza e perigo (Douglas, 2010). Como observa Rodrigues (2006) a respeito do nojo, nem todas substâncias produzidas e excretadas pelos corpos são tratadas socialmente da mesma forma. Em uma classificação dos fluidos, o leite materno seria, por exemplo, certamente encarado como superior ao catarro. Ainda assim, Shaw (2004) chama atenção para sentimentos de aversão ou nojo relacionados ao leite materno que, segundo a autora, se exacerbariam pelo fato desta ser uma substância que sai das mamas, parte do corpo feminino identificada como sexual.

Em UTIs neonatais, o leite materno é considerado uma substância com efeitos terapêuticos. Devido à maior facilidade de digestão em relação às fórmulas lácteas, à presença de fatores que auxiliam no desenvolvimento gastrointestinal e ao fator protetivo à enterocolite necrosante - condição potencialmente grave que pode se desenvolver em prematuros -, o leite materno é considerado o alimento ideal para bebês que se encontram internados. Ao mesmo tempo, por conta, principalmente, da separação física entre mãe e bebê, não é incomum que mães de bebês internados demorem mais para começar a produzir leite, ou tenham dificuldade de produzir volumes suficientes para suprir a demanda de seus filhos. Nesses casos, a OMS recomenda preferencialmente a oferta de leite materno obtido de um banco de leite humano, em comparação ao uso de fórmula (Carroll, 2014).

Porém, mesmo no contexto das UTIs, em que o leite materno é considerado especialmente valioso, há perspectivas e discursos concorrentes. Em uma etnografia realizada em bancos de leite e UTIs neonatais nos Estados Unidos, Carroll (2014) observou como as ambiguidades em relação ao leite materno vêm à tona no trato com os bebês, e nos rígidos protocolos de higiene e segurança em torno da coleta, armazenamento e manejo da substância. Nas UTIs, o leite é uma substância altamente regulada, que passa por diversos protocolos de segurança, descrita e entendida como uma terapia médica (Palmquist, 2015). Do mesmo modo, Bartle (2010) observou como, nos hospitais, o leite materno pode ser descrito tanto como um "salvador de bebês", produto essencial, precioso, escasso e quase mágico, ou como um fluido corporal potencialmente perigoso 
e contaminado, havendo grande preocupação com a possível transmissão de vírus e doenças.

Justamente pelas diretrizes de segurança, que incluem triagem da doadora e pasteurização do leite, o leite dos bancos de leite se distinguiria daquele obtido por compartilhamentos "informais" ou pela amamentação cruzada, pois extinguiria - ou, ao menos, minimizaria significativamente - as possibilidades de contaminação. Esse processo, altamente controlado, asseguraria a transformação de uma substância "arriscada" ou "potencialmente patogênica" em "segura" (Carroll, 2014; Cassidy; El-Tom, 2010).

Além disso, os bancos de leite removem qualquer relacionamento pessoal entre quem doa e quem recebe a substância. Após a doação, o nome da doadora desaparece, e o leite é analisado, pasteurizado e congelado, tornando-se leite "do banco". Comumente, o leite utilizado por um bebê é composto pela mistura do leite de diferentes doadoras. Nesse sentido, como observa Cevese (2015), os processos dos bancos de leite atuam também como formas de purificação do leite materno, removendo sua conotação subjetiva e corporal.

Se, como falamos, o leite materno e seu compartilhamento possuem diferentes sentidos, um exemplo etnográfico clássico que não pode deixar de ser mencionado é o chamado milk kinship islâmico, ou parentesco através do leite. Como explica Altorki (1980), a lei islâmica define três tipos de parentesco: pelo sangue, por afinidade e através do leite. O parentesco pelo leite diz respeito ao relacionamento entre uma criança e uma mulher, que não sua própria mãe biológica, que também a tenha amamentado. Tais regras de parentesco derivam da ideia de que os fluidos da mulher que amamenta pertencem ao seu marido, que é quem gera o leite, e definem com quem determinada pessoa pode ou não se casar. Embora tenha havido um declínio dessa prática, devido às mudanças nas estruturas familiares modernas, cada vez mais nucleares, e à mudança nos hábitos alimentares, com a disponibilidade do leite em pó, a ideia de parentesco através do leite ainda pode ser notada em alguns contextos ${ }^{9}$ (Altorki, 1980; Cassidy; El-Tom, 2010; Cevese, 2015; Fortier, 2001).

9 Certa noção de "mãe de leite" também aparece no contexto brasileiro, como veremos adiante, embora com peso distinto da lei islâmica do parentesco. 
Assim, em uma etnografia de bancos de leite de hospitais italianos, Cevese (2015) observou como mulheres imigrantes marroquinas conferiam sentidos ao leite materno conflitantes com aqueles atribuídos pelas equipes médicas. Em seu trabalho, a autora relata que uma das entrevistadas, uma mulher marroquina que havia dado à luz um bebê que precisou ficar internado na UTI, produzia mais leite do que ele necessitava para mamar. Quando a equipe do hospital propôs que ela doasse o excedente para o banco do hospital, a mulher recusou a doação - que era obrigatoriamente anônima - dizendo que precisaria conhecer o bebê que iria tomar seu leite, uma vez que ele se tornaria "irmão" de sua filha. A recusa foi justificada por ela, pois haveria risco de um dia os dois se casarem sem saberem que são parentes. Desse modo, Cevese mostra como a exigência de anonimato dos bancos de leite impactava essa noção de parentesco, evidenciando o significado diverso e mutável do leite materno dentro daquele contexto. ${ }^{10}$ Ainda de acordo com Cevese, tal conflito entre bancos de leite e o parentesco pelo leite entre alguns grupos de imigrantes é uma questão conhecida das equipes de saúde que trabalham com amamentação na Itália. Nas diretrizes dos bancos de leite italianos, é necessário que, além de obter o consentimento informado do responsável pelo bebê que receberá o leite, a equipe de saúde explique as diferenças entre amas de leite, práticas de amamentação cruzada e o leite do banco, informando que este é pasteurizado e tratado como um dispositivo terapêutico sem equivalência às outras práticas.

Como vimos, portanto, o anonimato e a esterilidade dos bancos de leite humano se chocam com a noção de parentesco através do leite, revelando os diferentes sentidos e as diferentes relações mediadas por essa substância. Já no caso do Brasil, tanto as perspectivas em torno da amamentação como o próprio processo de surgimento dos primeiros bancos de leite no século XX dizem respeito a contextos específicos que, como veremos a seguir, foram marcados pela escravidão e desigualdades sociais.

10 Em um contexto etnográfico similar, Elena Soler (2017) discute o conflito entre a ideia de parentesco e a doação de leite anônima em Barcelona, Espanha, entre mulheres mulçumanas marroquinas. 


\section{Amas de leite como problema, bancos de leite como solução}

Era muito frequente que mulheres negras escravizadas atuassem como amas de leite durante o período de escravidão no Brasil. Embora mulheres brancas, minoritariamente, também trabalhassem como amas antes e depois da abolição, as raízes dessa prática na escravidão são profundas, permanecendo seu entendimento, até hoje, fortemente racializado (Langland, 2019).

Numerosas teses médicas do final do século XIX, no Brasil, foram dedicadas a condenar a prática das amas de leite, e a exigir sua regulamentação, com exames médicos obrigatórios frequentes (Koutsoukos, 2009; Langland, 2019). Koutsoukos (2009) analisa os discursos médicos sobre amamentação nesse período e observa que o aleitamento era dividido em quatro modos: materno, artificial, mercenário ou misto. $\mathrm{O}$ aleitamento materno era considerado a forma superior de alimentação, fruto do amor da mãe por seu filho. No outro extremo, o aleitamento artificial - com leite animal, como de vaca ou cabra, e, posteriormente, também com leite condensado diluído e farinha láctea - era, nesse momento, considerado o mais inadequado, e somente deveria ocorrer quando a mãe não pudesse amamentar ou contratar uma "boa" ama de leite. $\mathrm{O}$ aleitamento mercenário, portanto, era a melhor opção para os casos em que a própria mãe não amamentava seu filho, "quer por impossibilidade, quer por má vontade" (Reis, 1882 apud Koutsoukos, 2009, p. 309). Porém, essa era uma prática que demandava inspeção rigorosa, e diferentes aspectos da saúde das amas deveriam ser levados em conta, como doenças prévias, dieta, hábitos de vida e temperamento, pois se acreditava que através do leite seriam transmitidas também "qualidades culturais" da nutriz:

Sobre as doenças físicas, os médicos costumavam alegar que as amas poderiam transmitir, além das já citadas febre amarela e cólera, varíola, tuberculose, sífilis, escarlatina, malária, escrófulas, vermes, sarnas, parasitas de cabelo e até mesmo lepra. As doenças morais, por sua vez, estariam presentes no leite sob a forma de "germes", que conteriam disposições hereditárias da escrava e se desenvolveriam mais tarde nos pequenos entes, a exemplo da suposta predisposição das escravas para a promiscuidade. (Koutsoukos, 2009, p. 310-311).

As amas eram vistas com grande desconfiança pelos médicos. O próprio termo "amamentação mercenária", como aponta Langland (2019), remeteria 
a uma suposta falta de sentimento materno "natural" daquela mulher em relação aos seus próprios filhos. Além disso, o racismo também era expresso nas crenças sobre a qualidade do leite das amas, e, como observa Carula (2012, p. 201), "a possibilidade de infectar moralmente os infantes, deturpando seu caráter, demonstra o perigo que os cativos representavam para as famílias brancas no imaginário desses homens de ciência". Nesse sentido, o aleitamento materno, ao mesmo tempo que protegeria as crianças desse perigo, possibilitaria uma mudança na ordem familiar alinhada às propostas de modernização do país, por meio de um ambiente familiar higiênico mais distante das práticas que haviam permanecido mesmo com a abolição da escravidão (Carula, 2012).

A partir do início do século XX, houve um expressivo avanço tecnológico na indústria de laticínios, levando a uma crescente oferta de leites industrializados. Assim, como pontuam Souza e Almeida (2005), esses novos produtos voltados à alimentação infantil foram acompanhados de estratégias agressivas de marketing, tornando-se uma alternativa cada vez mais valorizada pelos médicos. Como colocam os autores, "as soluções para os problemas e as dificuldades que surgiam no curso da amamentação passaram a compor uma equação cujo resultado, invariavelmente, apontava para uma única direção o uso dos leites industrializados" (Souza; Almeida, 2005, p. 36).

Por outro lado, concomitante a esse crescimento da indústria láctea, Langland (2019) observa como as ideias sobre as mulheres que trabalhavam como amas de leite - que, como vimos, refletem estereótipos em torno de classe e raça - influenciaram o desenvolvimento dos bancos de leite humano no Brasil, no início do século XX. Como argumenta a autora, durante grande parte do século XX, a prática da amamentação com amas de leite continuou a ocorrer no Brasil, e a história da amamentação com amas e o surgimento dos bancos de leite estão profundamente entrelaçados. Paralelamente ao trabalho das amas, portanto, e também ao avanço da indústria de leite, na década de 1940 alguns médicos começaram a organizar os primeiros bancos de leite humano no Brasil. Um desses fundadores, o médico Martagão Gesteira, dirigiu-se em 1947 ao público em uma conferência de pediatria, afirmando que: "A ama de leite mercenária é um problema. O banco de leite é a solução" (Gesteira, 1948 apud Langland, 2019, p. 1, tradução nossa). 
Almeida (1999) divide a história dos bancos de leite no Brasil em duas fases. A primeira fase tem início com a implementação do primeiro banco, em 1943, no então Instituto Nacional de Puericultura, atualmente Instituto Fernandes Figueira (IFF) da Fundação Oswaldo Cruz (Fiocruz). Essa primeira fase vai até 1985, quando haveria uma ruptura com o paradigma original e a constituição de um novo modelo, vigente até a atualidade.

Nessa primeira fase, para obter o leite para abastecer os bancos, os médicos se voltavam para mulheres pobres, e, em sua maioria, negras, consideradas as "fontes" ideais para os bancos. Em busca de doadoras, mulheres eram recrutadas nas maternidades públicas e clínicas. Uma relação comercial, de compra e venda, era estabelecida, sendo sempre oferecida alguma forma de remuneração - geralmente pagamento em dinheiro por doação ou por volume de leite doado, além de pequenos benefícios, como lanches -, e a venda do leite era forma de sustento para muitas (Almeida, 1999; Langland, 2019).

O entrelaçamento entre amas de leite e os bancos se explicita na seguinte colocação de Almeida (1999, p. 96): "Os bancos de leite eram de fato as amas-de-leite do século XX, e a doação, um grande e lucrativo negócio." Langland (2019), porém, critica esta afirmação. Para a autora,

teria sido mais prudente dirigir suas críticas àqueles que exploravam as amas do que a elas próprias. Os primeiros bancos de leite não eram as amas do século XX, mas eram instituições que refletiam, projetavam e fortaleciam ideias profundamente problemáticas sobre amas e sobre as mães que ordenhavam seu leite para bebês em necessidade. (Langland, 2019, p. 7, tradução nossa).

Se na primeira fase dos bancos de leite houve uma continuidade com a exploração do trabalho das amas, a partir de 1985 Almeida (1999) observa uma ruptura nesse modelo. Uma importante modificação foi a transformação dos bancos em instituições de apoio e promoção da amamentação, e o encerramento das trocas monetárias, passando as doações a ocorrer exclusivamente de modo voluntário.

Também na década de 1980, com a epidemia do HIV/AIDS e a descoberta de que o vírus poderia ser transmitido através do leite, houve a necessidade de procedimentos mais complexos para triagem e processamento do leite materno, o que resultou no fechamento de vários bancos de leite ao redor 
do mundo.1 Bar-Yam (2010), por exemplo, aponta que, nos Estados Unidos, havia cerca de 30 bancos de leite até o início dos anos 1980, e menos de dez ao final da mesma década. Com o decorrer dos anos de 1990, porém, o interesse pelos bancos de leite foi sendo renovado. Já em outros países, como Austrália e Nova Zelândia, todos os bancos foram fechados, tendo sido reabertos apenas recentemente, 30 anos depois, na década de 2010 (Bartle, 2010; Cassidy; El-Tom, 2010; Long, 2003).

No caso do Brasil, considerado referência mundial em relação aos bancos de leite, com uma rede de mais de 200 bancos articulados (Almeida, 1999), a pasteurização rapidamente se tornou procedimento obrigatório, além de terem sido adotados novos procedimentos de coleta, armazenamento e distribuição, bem como controle de qualidade (Almeida; Novak, 1994 apud Almeida, 1999, p. 104). Com isso:

Esta nova realidade operacional possibilitou que se enfrentassem com tranquilidade técnica os agravos e riscos decorrentes do advento da AIDS. Enquanto em várias regiões do mundo os bancos de leite foram fechados, por temor a questões de segurança operacional e risco biológico, o Brasil viveu um franco e seguro processo de expansão, uma vez que já haviam sido consolidados os cuidados essenciais para garantir a qualidade do leite humano ordenhado. (INAN, 1994 apud Almeida, 1999, p. 109).

Nota-se, portanto, que a forma pela qual os bancos de leites brasileiros contornaram o advento da AIDS foi decisiva para sua manutenção no país, bem como para a propagação do modelo e de seu reconhecimento internacional hoje. Simultaneamente, tornaram-se atores centrais na produção de discursos

11 Para Cassidy e El-Tom (2010), a comparação entre bancos de leite e de sangue é instrutiva. Embora os bancos de leite tenham sido fechados, ninguém defendeu o fechamento de bancos de sangue nesse período, apenas a necessidade de testes e protocolos rigorosos. Para os autores, presumivelmente, isso ocorre por não haver indústrias multibilionárias de "sangue artificial" que possam reivindicar a substituição de sangue de doadores. Ao mesmo tempo, Gribble e Hausman (2012) observam que a comparação com a transfusão de sangue, prática regulamentada e mediada pela medicina, faz com que o compartilhamento do leite materno seja visto como uma atividade que ocorre raramente, e apenas sob supervisão médica. Entretanto, o leite humano não é um medicamento e, embora seja um fluido corporal, não é como o sangue, sendo feito justamente para ser compartilhado, isto é, ingerido por outra pessoa. 
legítimos sobre amamentação no país, com um papel decisivo nas concepções de segurança e risco do leite materno em seu compartilhamento, impactando em modelos de família e maternidade derivadas dessas noções. Ocorre, entretanto, que tal fenômeno terminou também por invisibilizar e produzir um silenciamento público em torno de outras formas de compartilhamento do leite materno, o que não necessariamente acontece em outros países onde as políticas de amamentação se consolidaram de modo distinto.

\section{HIV e o perigo da contaminação pelo leite}

Van Esterik (2010) chama atenção para a falta de pesquisas em torno do leite materno como um fluido de transporte ou contágio para o HIV, em comparação com o estudo de outros fluidos como o sêmen e o sangue. A autora afirma que a questão não é vista como um problema de pesquisa legítimo, frente a outros assuntos considerados mais relevantes, pois se considera que o "problema" pode ser facilmente "resolvido" com o uso da fórmula e com a proibição da amamentação por mulheres soropositivas. Como observa a autora, o discurso dos profissionais de saúde, ao aconselhar gestantes HIV positivas, muda rapidamente de "o leite materno é o melhor alimento para o seu bebê" para "o leite materno pode matar seu bebê".

Essa forma de se encarar a questão, porém, revela desigualdades, e faz com que surjam dilemas, principalmente em países mais pobres, em que a população não tem a possibilidade de comprar e oferecer a fórmula de maneira segura, e em que a amamentação é considerada uma das práticas mais eficazes para prevenção da mortalidade infantil. Levando em conta tal dilema, a OMS recomenda, nesses casos, o aleitamento materno exclusivo para mulheres infectadas pelo HIV nos primeiros seis meses de vida do bebê, a menos que a reposição seja aceitável, viável, acessível, sustentável e segura antes desse período, devendo, então, ser evitada (WHO, 2006 apud Van Esterik, 2010). Assim, enquanto países desenvolvidos ainda recomendam a alimentação com fórmula como modo de se erradicar o risco de transmissão vertical do HIV, países em desenvolvimento muitas vezes optam pela amamentação "protegida" por antirretrovirais. As estratégias utilizadas dependem de inúmeros fatores, e são, portanto, contextuais (Desclaux; Alfieri, 2015). 
A ideia do leite materno como poluente, entretanto, é anterior à epidemia do HIV/AIDS. Como vimos em relação às amas de leite, historicamente, não apenas a saúde da nutriz era vista como um fator de risco potencial ao bebê, mas também seu caráter moral (Carula, 2012; Koutsoukos, 2009; Langland, 2019). Mais recentemente, discursos e práticas biomédicas continuam a definir o leite materno como um risco biológico em potencial. Há a ideia de que o leite materno é impuro e contaminante, em oposição a uma suposta esterilidade da fórmula (Shaw, 2004). Nesse sentido, Hausman (2010) analisou reportagens midiáticas, nos Estados Unidos, que relatavam um possível caso de transmissão vertical, através do leite materno, do vírus do Nilo Ocidental (doença transmitida pela picada de mosquitos infectados). No caso repercutido nos jornais, uma mãe doente havia amamentado seu bebê, que não desenvolveu qualquer sintoma da doença. A autora observa que é provável que o bebê tenha adquirido uma forma mais branda da doença, uma vez que os anticorpos da mãe também são transmitidos pelo leite materno. Porém, em vez de se enfatizar propriedades de fortalecimento imunológico da amamentação e do leite materno, as reportagens focavam nos temores da amamentação como potencial vetor para infecção. ${ }^{12}$ Para Hausman, tal forma de se olhar para a amamentação não seria um caso isolado, mas um reflexo da intensa medicalização da gravidez, parto e cuidados infantis.

Embora não tenhamos relatos de redes informais de compartilhamento de leite materno no Brasil, essa é uma prática cada vez mais comum em países como os Estados Unidos, fomentada principalmente pela internet. Em sua pesquisa, Palmquist (2015) analisa páginas e grupos em redes sociais destinadas ao "compartilhamento altruísta informal" de leite materno - termo que a autora utiliza para o diferenciar da distribuição através de redes de banco de leite. Nesses grupos, o leite é procurado tanto por mães cuja produção é menor do que a demanda de seus filhos como também por pais e mães adotivos, por exemplo. Para Palmquist, o compartilhamento informal do leite materno pode ser encarado como parte de um processo de desmedicalização - ou resistência

12 Na atualidade, a pandemia de Covid-19 coloca questões similares em relação à possibilidade de transmissão vertical. Ainda em março de 2020, no início da chegada do vírus ao Brasil, o Ministério da Saúde e a Sociedade Brasileira de Pediatria se manifestaram recomendando que o aleitamento fosse continuado, mesmo em casos de nutrizes contaminadas (Portal de Boas Práticas em Saúde da Mulher, da Criança e do Adolescente, 2020). 
à medicalização - da amamentação. Em defesa da prática, a autora argumenta que o compartilhamento do leite é uma forma poderosa de unir famílias, que tensiona e perturba o discurso de que a amamentação é um ato biológico da maternidade limitado à própria prole.

Essa prática, porém, é classificada como bastante arriscada por muitos profissionais de saúde. Nas palavras de Kim Updegrove, presidente da Rede de Bancos de Leite Humano Norte-Americana: "Compartilhar um fluido corporal, que potencialmente pode ter bactérias e vírus, é perigoso. É como brincar de roleta russa com a vida do seu filho" (Updegrove, 2013 apud Palmquist, 2015, p. 33, tradução nossa). Nesse sentido, Palmquist (2015) analisa estratégias utilizadas pelas famílias, ao buscarem doações de leite, para triar possíveis riscos de contaminação. Como observa a autora, acordos são feitos caso a caso, e, com frequência, doadoras disponibilizam seus exames médicos (feitos, por exemplo, durante o pré-natal) para quem deseja obter o leite. Além disso, é comum que sejam realizadas perguntas sobre hábitos da dieta da doadora (se faz uso, por exemplo, de cafeína, álcool, remédios, laticínios), e o encontro presencial entre doadora e receptores também é citado como um modo de tornar o compartilhamento do leite mais confortável e seguro.

Essa administração de possíveis riscos do compartilhamento informal de leite materno também é explorada por Falls (2017). A autora observa que, nesses grupos, são utilizadas noções fora dos métodos científicos racionais - como instinto e sentimentos de confiança - para decidir com quem compartilhar ou de quem receber leite materno. Há também uma hierarquia das necessidades das famílias que receberiam o leite. Bebês menores, adotivos, ou de mães que possuíam alguma doença, eram considerados "preferenciais" em relação a outros casos, e não era infrequente que doadoras quisessem saber mais sobre as famílias e as características do bebê que receberia a doação. Além disso, embora o grupo analisado por Falls só permitisse doação, há grupos destinados também à comercialização do leite materno. A compra e venda de leite, porém, é considerada, entre as pessoas entrevistadas pela autora, como uma prática mais arriscada do que a doação, pois, para obter maior lucro, acredita-se que muitos poderiam diluir o leite em água ou misturá-lo com leite de vaca. ${ }^{13}$

13 Além desses argumentos, podemos pensar no dinheiro como um elemento com o potencial de, por si só, "poluir" o leite materno, como já vimos nas acusações feitas às amas "mercenárias". 


\section{De volta ao contexto brasileiro}

Diferente do caso americano, contudo, o cenário brasileiro contemporâneo parece ser potente para uma compreensão do compartilhamento de leite materno não institucionalizado em uma lógica menos comercial e pautada, principalmente, em redes de ajuda mútua e reciprocidade na circulação de crianças, comuns sobretudo entre as classes populares brasileiras. Claudia Fonseca $(2002,2006,2012)$ ressalta a importante ênfase que se dá entre esses segmentos populacionais a outras possibilidades de vínculos familiares, que expandem e desestabilizam modelos vistos como tradicionais de família, especialmente entre as classes mais abastadas. A mãe, nesse caso, pode ser uma ou mais de uma, entre tantas opções. Como bem resumiu uma das crianças participantes da pesquisa da autora: ao ouvir uma conversa sobre suas mães, ela "parecia encantada com o grande número de mães que tinha: ‘Três', ela explicava. “A mãe de leite, a mãe de criação e a mãe que me ganhou'” (Fonseca, 2006, p. 24).

Antropólogas e outras estudiosas das noções de cuidado, família e parentesco vêm apontando para a necessidade de compreensão das redes de ajuda mútua em tais configurações, como na noção de "circulação de crianças" proposta originalmente por Fonseca. Nesses trabalhos, incorpora-se uma perspectiva que faz eco às proposições de uma "ética do cuidado" feminista rompendo com as ideias de dependência e autonomia tão marcantes da ideologia do individualismo moderno e reforçando a prevalência das relações de interdependência e reciprocidade (Debert; Pulhez, 2017; Mol, 2010; Tronto, 2009). Ao trazer esse olhar para a realidade da população brasileira, ressalta-se a existência de variados "arranjos de cuidado", que se estabelecem no cotidiano e são dependentes de relações de curta, média e longa duração (Fazzioni, 2018). As dificuldades e fragilidades com as quais muitas vezes esses arranjos se estabelecem tem como marca a ausência e ineficiência de políticas de Estado que garantam uma maior democratização da organização social do cuidado. Neste processo, desigualdades de gênero, classe e raça são muitas vezes acentuadas pelas próprias políticas públicas voltadas de algum modo para o cuidado (incluindo serviços de assistência, saúde e educação), como demonstra o trabalho de Fernandes (2019).

Embora a referência histórica mais imediata ao se falar em amamentação cruzada seja normalmente a das amas de leite, em sua relação com a escravidão 
ou seu caráter mercenário, como demonstramos anteriormente, a existência de tal prática em um ambiente íntimo e doméstico, como sendo aquela que persiste na realidade brasileira, aponta para dois sentidos. Por um lado, para uma particularidade dos modelos e condições sociais de maternagem entre a maior parte dessa população, como exemplificado acima, e, por outro, para um olhar enviesado da ciência para o espaço privado e doméstico, no que tange ao tema do cuidado com crianças.

A amamentação exige intensa disponibilidade e dedicação. Como outras pesquisas já demonstraram, os fatores que influenciam a amamentação são bastante complexos, esbarrando em uma série de complicadores individuais e em atravessamentos econômicos, sociais e políticos respectivos às realidades dessas mulheres (Almeida; Novak, 2004; Nakano, 2003). Além das dificuldades fisiológicas e psicológicas, pode-se destacar também questões trabalhistas, como o pouco tempo de licença-maternidade para a maior parte das brasileiras ou vínculos informais de trabalho que implicam muitas vezes retorno quase imediato após o nascimento dos filhos às atividades laborais. Violência doméstica é também um dos fatores que podem dificultar tal prática entre outras inúmeras variáveis..$^{14}$ No entanto, ao procurar responder sobre o porquê de a maior parte das mulheres brasileiras não amamentar exclusivamente até os seis meses, conforme preconizado pelo Ministério da Saúde, muitas pesquisas deixam de lado ou invisibilizam algo fundamental do ponto de vista das políticas de saúde: como elas alimentam seus filhos, quando deixam de amamentar ou não amamentam exclusivamente.

Enquanto fórmulas infantis são consideradas o principal e melhor substituto para o leite materno em crianças sem comorbidades, dados indicam que somente $23 \%$ das crianças que não são alimentadas exclusivamente ao peito até os seis meses consomem fórmulas infantis. $\mathrm{O}$ inquérito nacional realizado em 2013 (Brasil, 2015) destaca a prevalência do uso de leite de vaca como principal alimento complementar até os seis meses. A justificativa diz respeito, evidentemente, ao alto custo das fórmulas infantis comparado ao do leite de vaca. Vale notar ainda que, apesar de os bancos de leite serem a principal

14 Ver, por exemplo, os trabalhos de Bustamante et al. (2011), Mariano et al. (2016) e Ribeiro et al. (2017) para análises de situações em que os fatores citados podem interferir nos processos de amamentação. 
recomendação para as mães que desejam doar o seu leite, no caso daquelas que não conseguem amamentar por qualquer razão, o acesso ao leite dos bancos de leite não está facilmente disponível, sendo restrito aos pacientes atendidos pelos hospitais ligados à rede de bancos de leite humano. ${ }^{15} \mathrm{~A}$ amamentação cruzada emerge, portanto, também enquanto solução para os vários atravessamentos que permeiam o processo de amamentar. ${ }^{16}$

Em uma das cenas iniciais de um documentário recente sobre amamentação - intitulado De peito aberto (2018) ${ }^{17}$ - é possível observar uma situação que demonstra a naturalidade com a qual a amamentação cruzada é pensada enquanto solução para uma das personagens acompanhada pelo filme. Elaine Barbosa é mãe de um bebê de pouco mais de um mês, seu primeiro filho. A personagem, paulistana da zona leste, uma mulher negra com idade próxima aos 30 anos, realiza ao mesmo tempo o desejo de ter um filho e a conclusão do curso de graduação em uma universidade. A noite da festa de formatura é um momento muito esperado por ela, que também havia investido intensamente na amamentação exclusiva do filho, à revelia dos conselhos dados pela sogra, que queria que o bebê também fosse alimentado com leite artificial na

15 Cabe observar que os estoques de bancos de leite humanos são voltados, prioritariamente, aos casos encaminhados pela rede local de saúde, respeitando uma ordem de maior necessidade que inclui situações como: recém-nascido prematuro ou de baixo peso, que não suga, e recém-nascido com outras doenças ou condições agravantes (Agência Nacional de Vigilância Sanitária, 2008). No caso de outras dificuldades, os bancos de leite normalmente oferecem apoio e orientação à amamentação, mas não o acesso ao leite disponível pela doação.

16 Pesquisando mulheres, na Nova Zelândia, que haviam praticado amamentação cruzada, Shaw (2007) observa que algumas de suas entrevistadas relataram que compartilhar a amamentação com amigas ou parentes seria uma estratégia para equilibrar demandas de trabalho com demandas de cuidados com filhos, a partir de relações de intimidade, confiança e generosidade. De modo similar, em pesquisa com mães australianas, Long (2003) observou que mulheres que haviam praticado amamentação cruzada se referiam, primordialmente, a questões que não estavam vinculadas a modelos biomédicos de riscos de exposição a fluidos corporais. O compartilhamento de leite era algo comum entre elas, e ocorria desde em casos de bebês prematuros em que a mãe não conseguia ordenhar leite suficiente - sendo compartilhado através de mamadeiras ou outros recipientes -, a casos em que amigas se revezavam no cuidado e alimentação dos filhos.

17 O documentário de Graziela Mantoanelli, que estreou em 2019, conta a história de seis mães de diferentes realidades socioculturais durante os primeiros 180 dias de vida dos seus bebês na cidade de São Paulo, e as dificuldades que enfrentam na amamentação. O filme alterna cenas com as mulheres e depoimentos de especialistas. Mais informações no site do filme (De peito aberto, [2019]). 
mamadeira. Na noite da festa, então, o dilema se impõe sobre quem ficaria cuidando do bebê para que ela pudesse celebrar sua formatura. É a mãe de Elaine, ao fim, quem sugere a ideia de que ele fique aos cuidados de uma prima, cujo filho era alguns meses mais velho e também alimentado ao peito. Ao chegar na casa da prima, o documentário retrata a apreensão de ambas com a situação. A prima pega o bebê no colo e ele chora, ela então tenta fazer com que ele pegue o peito. Elaine diz: "Ele está estranhando, demora um pouquinho para pegar mesmo." A câmera foca no filho da prima, dormindo. Alguns segundos depois o bebê de Elaine para de chorar e começa a mamar na prima, ela logo sorri e, em seguida, a câmera foca no rosto de Elaine, a mãe, que dá um grande sorriso. A próxima cena é no carro a caminho da festa, e, depois, de Elaine se divertindo e dançando na festa de formatura.

A cena oferece um mote interessante para que indaguemos, como propõe Lee (2013), que, se a amamentação pode ser vista como um obstáculo potencial à divisão das práticas de cuidado infantil, não poderia a amamentação cruzada ser encarada como um modo de questionamento da noção de que o aleitamento é um trabalho que não pode ser compartilhado? A história de Elaine e sua prima na noite da festa de formatura, tão bem capturada pelo filme de Graziela Mantoanelli, revela algumas das inúmeras complexidades desse processo. A escolha sobre quem ficaria com o bebê naquele dia não fica restrita somente a Elaine e seu marido, embora ele estivesse também envolvido na situação. Foi a avó materna quem envolveu a prima na história, sugerindo que, pela "questão do peito", seria melhor que o bebê ficasse com ela. Se na situação retratada foi a prima quem cumpriu tal função, em outros inúmeros casos no Brasil, sobretudo entre as camadas populares, observam-se vizinhas, amigas, cunhadas e outras mulheres sem necessária relação de consanguinidade exercendo essa ou outra tarefa de cuidado em prol umas das outras.

Embora o tema ainda careça de investimentos de pesquisa, podemos aqui especular sobre quem são as mulheres sujeitos que compõem as experiências da amamentação cruzada hoje em termos de classe e raça no Brasil. A partir de tudo que foi até aqui exposto, é possível, sem muitas hesitações, sugerir que são principalmente as mulheres negras e mais empobrecidas aquelas cujos filhos são amamentados por outras mulheres e também amamentam os filhos de suas amigas, vizinhas e familiares. Assim, embora não seja o objetivo principal deste artigo, ele se soma aos esforços mais recentes do feminismo em 
perspectiva decolonial (Miñoso, 2017) e da crítica a um feminismo individualista e neoliberal (Arruzza; Bhattacharia; Fraser, 2019), ao olhar para o tema da amamentação cruzada e refletir sobre certa colonialidade do saber que retroalimenta uma pauta feminista identitária e meritocrática eurocentrada, com foco em mulheres brancas e de classes médias e altas.

Não pretendemos neste artigo levantar dúvidas de que a amamentação é uma prática que deve ser estimulada e orientada a partir de políticas públicas. Mas refletimos e questionamos sobre quais são os custos da invisibilidade das experiências, necessidades e possibilidades reais da população nas pesquisas e nas práticas que sustentam essas políticas. Nota-se, por fim, que as concepções em torno do leite materno e seu compartilhamento no Brasil partem de origens históricas bastante específicas e de uma conformação do campo da atenção à saúde materno-infantil também marcado por inúmeras particularidades as quais, de certo modo, passam ao largo tanto da realidade socioeconômica de muitas famílias brasileiras quanto das mais diversas formas de família e maternidade existentes nessa mesma sociedade.

\section{Considerações finais}

Neste trabalho, refletimos sobre diversos sentidos atribuídos ao leite materno e as concepções de diferentes atores sociais e mecanismos que orientam e regulam a amamentação.

A partir da repercussão de casos de amamentação cruzada, observamos o esforço de órgãos oficiais e profissionais de saúde em alertar que esse não seria um "ato de amor", mas algo que traria riscos à saúde dos bebês. Como vimos, a história do surgimento dos bancos de leite no Brasil se entrelaça ao combate à atuação das amas de leite - tendo os bancos sido apresentados como "solução" para esse "problema". A mesma relação aparece nos discursos atuais sobre a amamentação cruzada. Nas repercussões dos casos analisados, há uma ligação entre a prática e a "antiga atuação" das amas. Nesse sentido, a amamentação cruzada parece ser apresentada como algo que também poderia ser combatido ou solucionado com os bancos de leite, agora capazes de orientar mulheres a amamentar seus próprios filhos, e possibilitar, para bebês internados, o compartilhamento do leite a partir de rígidos protocolos sanitários. 
É preciso observar que a proscrição da amamentação cruzada, concomitante à recomendação da amamentação exclusiva até os seis meses, fomenta certo tipo de subjetividades e modelo de família. Como procuramos argumentar, esse modo de olhar para a amamentação e o compartilhamento de leite não leva em conta dificuldades enfrentadas pelas mulheres, diferentes arranjos de cuidados, o aspecto relacional da amamentação e as vivências da maternidade para além do escrutínio médico.

\section{Referências}

AGÊNCIA NACIONAL DE VIGILÂNCIA SANITÁRIA. Banco de leite humano: funcionamento, prevenção e controle de riscos. Brasília: Anvisa, 2008.

ALMEIDA, J. A. G. de. Amamentação: um híbrido natureza-cultura. Rio de Janeiro: Editora Fiocruz, 1999.

ALMEIDA, J. A. G. de. Fiocruz e rBLH esclarecem perigos da amamentação cruzada. Rio de Janeiro: rBLH Brasil, 28 mar. 2018. Disponível em: https://rblh.fiocruz.br/fiocruz-e-rblh-esclarecem-perigos-da-amamentacao-cruzada. Acesso em: 10 jul. 2020.

ALMEIDA, J. A. G. de; NOVAK, F. R. Amamentação: um híbrido natureza-cultura. Jornal de Pediatria, Rio de Janeiro, v. 80, n. 5, supl., p. s119-s125, 2004.

ALTORKI, S. Milk-kinship in Arab society: an unexplored problem in the ethnography of marriage. Ethnology, [s. l.], v. 19, n. 2, p. 233-244, 1980.

ARRUZZA, C.; BHATTACHARIA, T.; FRASER, N. Feminismo para os 99\%: um manifesto. São Paulo: Boitempo, 2019.

BADINTER, E. Um amor conquistado: o mito do amor materno. Rio de Janeiro: Nova Fronteira, 1985.

BARBIERI, C.; COUTO, M. As amas de leite e a regulamentação biomédica do aleitamento cruzado: contribuições da socioantropolologia e da história. Cadernos de História da Ciência, São Paulo, v. 8, n. 1, p. 62-76, 2012.

BARSANTI, C.; CHENCINSKI, Y. M. Comunicado da SPSP sobre amamentação cruzada. São Paulo: Sociedade de Pediatria de São Paulo, 28 mar. 2018. Disponível em: https:// www.spsp.org.br/2018/03/28/comunicado-da-spsp-sobre-amamentacao-cruzada/. Acesso em: 10 jul. 2020. 
BARTLE, C. Going with the flow: contemporary discourses of donor breastmilk use and breastmilk in a neonatal intensive care setting. In: SHAW, R.; BARTLETT, A. Giving breastmilk: body ethics and contemporary breastfeeding practices. Bradford: Demetre Press, 2010. p. 122-133.

BAR-YAM, N. The story of the mothers' milk bank of New England. In: SHAW, R.; BARTLETT, A. Giving breastmilk: body ethics and contemporary breastfeeding practices. Bradford: Demetre Press, 2010. p. 97-109.

BLUM, L. Mothers, babies, and breastfeeding in late capitalist America: the shifting contexts of feminist theory. Feminist Studies, [s. l.], v. 19, n. 2, p. 291-311, 1993.

BRASIL. Ministério da Saúde. Portaria $n^{0}$ 2.415, de 12 de dezembro de 1996. Brasília: Ministério da Saúde, Gabinete do Ministro, 1996. Disponível em: https://bvsms. saude.gov.br/bvs/saudelegis/gm/1996/prt2415_12_12_1996.html. Acesso em: 15 ago. 2020.

BRASIL. Ministério da Saúde. Secretaria de Atenção à Saúde. Saúde da criança: aleitamento materno e alimentação complementar. Brasília: MS, 2015.

BUSTAMANTE, A. et al. Vivência da amamentação por trabalhadoras de uma indústria têxtil do Estado do Ceará, Brasil. Revista Brasileira de Enfermagem, Brasília, v. 64, n. 1, p. 66-71, 2011.

CARROLL, K. Body dirt or liquid gold? How the 'safety' of donated breastmilk is constructed for use in neonatal intensive care. Social Studies of Science, [s. l.], v. 44, n. 3, p. 466-485, 2014.

CARSTEN, J. A matéria do parentesco. R@U: revista de antropologia da UFSCar, São Carlos, v. 6, n. 2, p. 103-118, jul./dez. 2014.

CARULA, K. Perigosas amas de leite: aleitamento materno, ciência e escravidão em A Mãi de Família. História, Ciências, Saúde - Manguinhos, Rio de Janeiro, v. 19, supl., p. 197-214, 2012.

CASSIDY, T.; EL-TOM, A. Comparing sharing and banking milk: issues of gift exchange and community in the Sudan and Ireland. In: SHAW, R.; BARTLETT, A. Giving breastmilk: body ethics and contemporary breastfeeding practices. Bradford: Demetre Press, 2010. p. 110-121.

CASSIDY, T.; EL-TOM, A. Introduction. In: CASSIDY, T.; EL-TOM, A. (ed.). Ethnographies of breastfeeding: cultural contexts and confrontations. London: Bloomsbury Academic, 2015. p. 1-10. 
CEVESE, R. "Who knows if one day, in the future, they will get married...?": breastmilk, migration, and milk banking in Italy. In: CASSIDY, T.; EL-TOM, A. (ed.). Ethnographies of breastfeeding: cultural contexts and confrontations. London: Bloomsbury Academic, 2015. p. 99-109.

CONHEÇA os riscos e benefícios da amamentação cruzada. Balanço Geral MG, Belo Horizonte, 26 fev. 2020. 1 vídeo (3 min 46 s). Disponível em: https://www.youtube. com/watch?v=1fWT6dMlZ6Q. Acesso em: 10 jul. 2020.

CONSELHO REGIONAL DE MEDICINA DO ESTADO DO RIO DE JANEIRO. CREMERJ alerta para o risco da amamentação cruzada. Rio de Janeiro: CREMERJ, 28 mar. 2018. Disponível em: https://cremerj.org.br/informes/exibe/3862. Acesso em: 10 jul. 2020.

DE PEITO aberto. Direção: Graziela Mantoanelli. Produção: Leonardo Brant. São Paulo: Deusdará, 2018. Color. (77 min).

DE PEITO ABERTO. [Site do filme]. São Paulo: Deusdará, [2019]. Disponível em: https://www.depeitoaberto.net/filme. Acesso em: 10 ago. 2020.

DEBERT, G.; PULHEZ, M. (org.). Desafios do cuidado: gênero, velhice e deficiência. Campinas: Unicamp/IFCH, 2017.

DESCLAUX, A.; ALFIERI, C. Between proscription and control of breastfeeding in West Africa: women's strategies regarding prevention of HIV transmission. In: CASSIDY, T.; EL-TOM, A. (ed.). Ethnographies of breastfeeding: cultural contexts and confrontations. London: Bloomsbury Academic, 2015. p. 125-144.

DOUGLAS, M. Pureza e perigo. São Paulo: Perspectiva, 2010.

FALLS, S. White gold: stories of breast milk sharing. Lincoln: University of Nebraska Press, 2017.

FAZZIONI, N. Nascer e morrer no Complexo do Alemão: políticas de saúde e arranjos de cuidado. 2018. Tese (Doutorado em Antropologia e Sociologia) - Instituto de Filosofia e Ciências Sociais, Universidade Federal do rio de Janeiro, Rio de Janeiro, 2018.

FERNANDES, C. Figuras do constrangimento: as instituições de Estado e as políticas de acusação sexual. Mana, Rio de Janeiro, v. 25, n. 2, p. 365-390, 2019.

FONSECA, C. Mãe é uma só? Reflexões em torno de alguns casos brasileiros. Psicologia USP, São Paulo, v. 13, n. 2, p. 1-11, 2002.

FONSECA, C. Da circulação de crianças à adoção internacional: questões de pertencimento e posse. Cadernos Pagu, Campinas, v. 26, p. 11-43, 2006. 
FONSECA, C. Mães “abandonantes”: fragmentos de uma história silenciada. Revista Estudos Feministas, Florianópolis, v. 20, n. 1, p. 13-32, 2012.

FORTIER, C. Le lait, le sperme, le dos. Et le sang? Cahiers d'études africaines, [s. l.], v. 161, p. 97-138, 2001.

GIMENEZ, I. Gabi Brandt amamenta o sobrinho e nós te explicamos os perigos da amamentação cruzada. Pais\&Filhos, 9 jul. 2019. Disponível em: https://paisefilhos. uol.com.br/familia/gabi-brandt-amamenta-o-sobrinho-e-nos-te-explicamos-os-perigos-da-amamentacao-cruzada/. Acesso em: 10 jul. 2020.

GRIBBLE, K.; HAUSMAN, B. Milk sharing and formula feeding: Infant feeding risks in comparative perspective? Australasian Medical Journal, [s. l.], v. 5, n. 5, p. 275-283, 2012.

HAUSMAN, B. Risk and culture revisited: breastfeeding and the 2002 West Nile Virus scare in the United Sates. In: SHAW, R.; BARTLETT, A. Giving breastmilk: body ethics and contemporary breastfeeding practices. Bradford: Demetre Press, 2010. p. 175-187.

KOUTSOUKOS, S. 'Amas mercenárias': o discurso dos doutores em medicina e os retratos de amas - Brasil, segunda metade do século XIX. História, Ciências, Saúde Manguinhos, Rio de Janeiro, v. 16, n. 2, p. 305-324, 2009.

LANGLAND, V. Expressing motherhood: wet nursing and human milk banking in Brazil. Journal of Human Lactation, [s. l.], v. 35, n. 2, p. 1-8, 2019.

LEE, R. Breastmilk exchange and new forms of social relations. MP: an online feminist, [s. l.], v. 4, n. 1, p. 36-70, 2013.

LONG, D. Breast sharing: cross-feeding among Australian women. Health Sociology Review, [s. l.], v. 12, n. 2, p. 103-110, 2003.

MARIANO, L. et al. Aleitamento materno exclusivo e autoeficácia materna entre mulheres em situação de violência por parceiro íntimo. Texto \& Contexto Enfermagem, Florianópolis, v. 25, n. 4, p. 1-10, 2016.

MIÑOSO, Y. De por qué es necesario un feminismo descolonial: diferenciación, dominación coconstitutiva de la modernidade occidental y el fin de la política de identidad. Solar: revista de filosofía iberoamericana, [s. l.], v. 12, n. 1, p. 141-171, 2017.

MOL, A. Care: putting practice in theory. In: MOL, A.; MOSER, I.; POLS, J. Care in practice: on tinkering in clinics, homes and farms. Amsterdam: Transcript, 2010. p. 7-26. 
NAKANO, A. As vivências da amamentação para um grupo de mulheres: nos limites de ser "o corpo para o filho" e de ser "o corpo para si". Cadernos de Saúde Pública, Rio de Janeiro, n. 19, supl. 2, p. S355-S363, 2003.

PALMQUIST, A. Demedicalizing breastmilk: the discourses, practices, and identities of informal milk sharing. In: CASSIDY, T.; EL-TOM, A. (ed.). Ethnographies of breastfeeding: cultural contexts and confrontations. London: Bloomsbury Academic, 2015. p. 23-44.

PEREIRA, C. Prevalência de aleitamento cruzado e saberes sobre esta prática, entre as gestantes atendidas na Estratégia Saúde da Família do município de Belém, Estado do Pará. 2014. Trabalho de Conclusão de Curso (Graduação em Medicina) - Faculdade de Medicina, Universidade Federal do Pará, Belém, 2014.

POLÍCIA MILITAR DE MINAS GERAIS. Ato de amor. Belo Horizonte, 24 fev. 2020. Instagram: @pmmg.oficial. Disponível em: https://www.instagram.com/p/B890-jbB1GS/. Acesso em: 10 jul. 2020.

PORTAL DE BOAS PRÁTICAS EM SAÚDE DA MULHER, DA CRIANÇA E DO ADOLESCENTE. COVID-19 e aleitamento materno: orientações do MS, SBP e rBLH. Rio de Janeiro: Fundação Oswaldo Cruz, 18 mar. 2020. Disponível em: https://portaldeboaspraticas.iff.fiocruz.br/atencao-crianca/covid-19-e-aleitamento-materno-orientacoes-da-sbp-e-rblh/. Acesso em: 10 jul. 2020.

RIBEIRO, K. et al. A amamentação e o trabalho informal: a vivência de mães trabalhadoras. Revista Pró-UniverSUS, Vassouras, v. 8, n. 2, p. 3-9, 2017.

RODRIGUES, J. Tabu do corpo. Rio de Janeiro: Fiocruz, 2006.

SCHNEIDER, D. American kinship: a cultural account. Eglewood Cliffs: Prentice Hall, 1968.

SHAW, R. The virtues of cross-nursing and the 'yuk factor'. Australian Feminist Studies, [s. l.], v. 19, n. 45, p. 287-299, 2004.

SHAW, R. Cross-nursing, ethics, and giving breast milk in the contemporary context. Women's Studies International Forum, [s. l.], n. 30, p. 439-450, 2007.

SOLER, E. Bancos de leche, parentesco de leche e Islam. Restricciones alimentarias entre la población infantil en Barcelona. Dilemata, [s. l.], año 9, n. 25, p. 109-119, 2017.

SOUZA, L.; ALMEIDA, J. História da alimentação do lactente no Brasil: do leite fraco à biologia da excepcionalidade. Rio de Janeiro: Editora Revinter, 2005. 
STRATHERN, M. Necessidade de pais, necessidade de mães. Revista Estudos Feministas, Florianópolis, n. 2, p. 303-309, 1995.

TIBONI, M. Mama: um relato de maternidade homoafetiva. São Paulo: Dita Livros, 2019.

TRONTO, J. Moral boundaries: a political argument for an ethic of care. London: Routledge, 2009.

VAN ESTERIK, P. Vintage breast milk: exploring the discursive limits of feminine fluids. Canadian Theatre Review, [s. l.], n. 137, p. 20-23, 2009.

VAN ESTERIK, P. Breastfeeding and HIV/AIDS: critical gaps and dangerous intersections. In: SHAW, R.; BARTLETT, A. Giving breastmilk: body ethics and contemporary breastfeeding practices. Bradford: Demetre Press, 2010. p. 151-162.

VON SEEHAUSEN, M. et al. Fatores associados ao aleitamento cruzado em duas cidades do Sudeste do Brasil. Cadernos de Saúde Pública, Rio de Janeiro, v. 33, n. 4, e00038516, 2017.

VON SEEHAUSEN, M.; OLIVEIRA, M.; BOCCOLINI, C. Fatores associados ao aleitamento cruzado. Ciência \& Saúde Coletiva, Rio de Janeiro, v. 22, n. 5, p. 1673-1682, 2017.

WILSON, K. Other's milk: the potential of exceptional breastfeeding. New Brunswick: Rutgers University Press, 2018.

Recebido: 18/08/2020 Aceito: 06/07/2021 | Received: 8/18/2020 Accepted: 7/6/2021 